\title{
Two-Way Cross-Neutralization Mediated by a Shared P (VP4) Serotype between Bovine Rotavirus Strains with Distinct G (VP7) Serotypes
}

\author{
YUKIHISA MATSUDA, ${ }^{1}$ YUJI ISEGAWA, ${ }^{2}$ GERALD N. WOODE, ${ }^{3}$ SHILUN ZHENG, ${ }^{3}$ EIJI KAGA, ${ }^{4}$ \\ TOYOKO NAKAGOMI, ${ }^{5}$ SHIGEHARU UEDA, ${ }^{2}$ AND OSAMU NAKAGOMI ${ }^{4 *}$ \\ Animal Facilities for Experimental Medicine, ${ }^{1}$ Department of Laboratory Medicine, ${ }^{4}$ and Department of Microbiology, ${ }^{5}$ \\ Akita University School of Medicine, Akita 010, and Department of Preventive Medicine Research \\ Institute for Microbial Diseases, Osaka University, Suita 565, Japan, and Department \\ of Veterinary Pathobiology, College of Veterinary Medicine, Texas \\ A\&M University, College Station, Texas $77843^{3}$
}

Received 24 July 1992/Accepted 16 November 1992

\begin{abstract}
Among bovine rotavirus strains, there are three G serotypes (G6, G8, and G10) and three P (VP4) serotypes (PB1, PB2, and PB3, which are defined on the basis of strains NCDV, UK, and B223, respectively). Plaque reduction neutralization assays with hyperimmune antisera disclosed two-way antigenic relationships of strain KN-4 with strain KK-3 (G10, PB3) as well as with strains NCDV (G6, PB1) and 0510 (G6, PB2). Neutralization assays with monoclonal antibodies specific for G6, G10, and PB3 revealed that KK-3 and $\mathrm{KN}-4$ had the same P serotype (PB3) but that neither G6- nor G10-specific monoclonal antibody neutralized KN-4. Comparison of the VP7 gene sequence of $\mathrm{KN}-4$ with those of other bovine rotavirus strains indicated that $\mathrm{KN}-4$ was more similar to G6 bovine strains than to KK-3 and other G10 strains, suggesting that the G serotype of KN-4 was G6. From these results, we concluded that the two-way cross-neutralization between $\mathrm{KN}-4$ and NCDV or 0510 was mediated by shared G6 serotype specificity, whereas the two-way cross-neutralization between $\mathrm{KN}-4$ and KK-3 was mediated by shared $P$ serotype specificity $(P B 3)$. Thus, $K N-4$ and $K K-3$ represent the first reported example of a two-way antigenic relationship mediated only by the $P$ serotype. This article emphasizes the need for adopting a binary serotyping system and development of reagents which will enable classification of rotaviruses based on their $G$ and $P$ serotype specificities.
\end{abstract}

Group A rotaviruses are the most important etiological agents of acute diarrheal illness of the young of a number of mammalian species, including cattle (13). The virions possess two outer capsid proteins, VP7 (the product of gene segment 7,8 , or 9 depending on the strain) and VP4 (the product of gene segment 4). Both proteins are involved in virus neutralization, and they segregate independently (10, 21). The neutralization specificity carried on VP7 is designated the G serotype (for glycoprotein), and that carried on VP4 is designated the $\mathrm{P}$ serotype (for protease-sensitive protein) (6). There are at least $14 \mathrm{G}$ serotypes $(1-3,11,16$, $23,25,29)$ and $10 \mathrm{P}$ serotypes $(6,22)$ among mammalian and avian rotaviruses. Among group A bovine rotaviruses, three G serotypes (G6, G8, and G10) have been described under a unified serotyping scheme. Matsuda et al. (15) have recently shown that three $P$ serotypes are discriminated by crossneutralization studies and have proposed that $P$ serotypes of bovine rotaviruses be designated PB1 (represented by NCDV), PB2 (represented by UK, B641, or 0510), and PB3 (represented by KK-3 or B223) until a unified serotyping nomenclature for $\mathrm{P}$ serotypes, such as the one proposed by Estes and Cohen (6), is agreed upon.

As a natural consequence of the serotype of rotavirus being determined by two independent viral proteins, there are cases in which one-way (but not reciprocal) crossneutralization with hyperimmune antiserum between strains with distinct $G$ serotypes is observed $(9,10)$. Such antigenic bridging is explained by the sharing of the P serotype by the

\footnotetext{
* Corresponding author.
}

strains. Because the sharing of the $P$ serotype has never resulted in two-way cross-neutralization, it has been generally accepted that the demonstration of two-way crossneutralization with hyperimmune antisera is necessary and sufficient for defining two strains as being of the same $G$ serotype. In this article, we describe the first counterexample to this accepted wisdom, in which two-way crossneutralization mediated by the shared $P$ serotype (PB3) between two bovine rotavirus strains with distinct $G$ serotypes (G6 and G10) was observed.

\section{MATERIALS AND METHODS}

Viruses. The rotavirus strains used in this study were NCDV (G6, PB1) (17), 0510 (G6, PB2) (18), KK-3 (G10, PB3) (19), and KN-4 (19).

Hyperimmune antisera and monoclonal antibodies. Hyperimmune antisera to the rotavirus strains described above were made in guinea pigs by multiple injections of complete Freund's adjuvant containing partially purified virions, which were prepared by pelleting the infected culture supernatant at $36,000 \mathrm{rpm}$ for $2 \mathrm{~h}$ in a Hitachi RP42 rotor and sedimenting the pellet through $30 \%$ (wt/vol) sucrose at $38,000 \mathrm{rpm}$ for $3 \mathrm{~h}$ in a Hitachi RPS40-T rotor. Neutralizing monoclonal antibodies B223-N1, B223-N7, and B641-N2b (32) (prepared by S. Zheng et al.) were directed at VP4 of B223, VP7 of B223, and VP7 of B641, respectively. All monoclonal antibodies were produced in cell culture.

Plaque reduction neutralization assay. Serotyping was performed by plaque reduction neutralization assay. After activation with trypsin, approximately 40 PFU of virus was 
TABLE 1. Antigenic relationships among four bovine rotavirus strains examined by plaque reduction neutralization assay

\begin{tabular}{lrrrr}
\hline \multirow{2}{*}{\begin{tabular}{c} 
Virus (G and $\begin{array}{c}\text { P } \\
\text { serotypes) }\end{array}$ \\
\cline { 2 - 5 }
\end{tabular}} & \multicolumn{4}{c}{$\begin{array}{c}\text { Reciprocal of titer of hyperimmune serum } \\
\text { neutralization antibody to: }\end{array}$} \\
\cline { 2 - 5 } & NCDV & \multicolumn{1}{c}{0510} & KK-3 & KN-4 \\
\hline NCDV (G6, PB1) & $>51,200$ & 51,200 & 400 & 51,200 \\
0510 (G6, PB2) & $>51,200$ & 25,600 & 400 & 51,200 \\
KK-3 (G10, PB3) & $<200$ & $<200$ & 25,600 & 25,600 \\
KN-4 & $>51,200$ & $>51,200$ & 12,800 & 102,400 \\
\hline
\end{tabular}

incubated with antiserum dilutions (fourfold) for $1 \mathrm{~h}$ at $37^{\circ} \mathrm{C}$. The mixtures were inoculated into six-well plate cultures of MA104 cells, the cultures were overlaid with agarose containing $0.5 \mu \mathrm{g}$ of trypsin per $\mathrm{ml}$, and viral plaques were counted. Antibody titers were expressed as the highest dilution of antiserum neutralizing $60 \%$ or more of the input viruses.

Preparation of genomic RNA. The genomic RNAs of KK-3 and $\mathrm{KN}-4$ were extracted from purified virions with phenolchloroform and precipitated with ethanol as described previously (20).

Amplification of VP7 genes by reverse transcription and polymerase chain reaction (PCR). The VP7 genes of KK3 and KN4 were reverse transcribed from genomic doublestranded RNA with Rous-associated virus-2 reverse transcriptase (Takara Shuzo, Co., Inc., Kyoto, Japan) by using primers complementary to terminal regions of the VP7 gene of NCDV. The resulting full-length cDNA was amplified with Ampli-Taq DNA polymerase (Perkin-Elmer-Cetus, Norwalk, Conn.) and the same pair of primers described above. Amplification was performed for 25 cycles of $90^{\circ} \mathrm{C}$ for $1 \mathrm{~min}, 55^{\circ} \mathrm{C}$ for $2 \mathrm{~min}$, and $72^{\circ} \mathrm{C}$ for $3 \mathrm{~min}$.

Direct sequencing of the PCR product. Portions of cDNA generated by the PCR were determined by a modification of the dideoxy-chain termination method of Sanger et al. (24). The details of this method will be described elsewhere (12).

Nucleotide sequence accession number. The GenBank nucleotide sequence accession number for the KN-4 VP7 gene is $\mathrm{D} 12710$.

\section{RESULTS}

A distinct serotype is defined as a reciprocal 20 -fold or greater difference in plaque reduction neutralization titer when a candidate serotype is tested against prototype viruses representing established serotypes $(13,31)$. With this standard, two viruses are considered antigenically similar when a less-than-20-fold difference in titer between homologous and heterologous reactions is observed. Table 1 shows the results of cross-neutralization tests to determine the serotype of the $\mathrm{KN}-4$ strain. The $\mathrm{KN}-4$ strain was neutralized by hyperimmune antiserum to the KK-3 strain (G10, PB3) (the difference in titer was twofold). Correspondingly, the KK-3 strain was neutralized by hyperimmune serum to the $\mathrm{KN}-4$ strain (the difference in titer was fourfold). When the definition of the rotavirus serotype described above was adopted, KK-3 and KN-4 were considered to possess the same serotype. Because two-way cross-neutralization between two strains possessing the same $P$ serotype but different $G$ serotypes had never been reported in the literature, these results were initially interpreted as showing that KN-4 possessed G10 specificity. This interpretation was immediately challenged by the two-way crosses observed
TABLE 2. Antigenic characterization of four bovine rotavirus strains by plaque reduction neutralization assay with monoclonal antibodies

\begin{tabular}{lccc}
\hline \multirow{2}{*}{$\begin{array}{c}\text { Virus (G and } P \\
\text { serotypes) }\end{array}$} & \multicolumn{3}{c}{$\begin{array}{c}\text { Reciprocal of neutralization titer of } \\
\text { monoclonal antibody: }\end{array}$} \\
\cline { 2 - 4 } & B223-N1 & B223-N7 & B641-N2b \\
\hline NCDV (G6, PB1) & $<100$ & $<100$ & 2,400 \\
0510 (G6, PB2) & $<200$ & $<200$ & 1,600 \\
KK-3 (G10, PB3) & 1,200 & 12,800 & $<100$ \\
KN-4 & 800 & $<100$ & $<100$ \\
\hline
\end{tabular}

between KN-4 and NCDV (G6, PB1) and between KN-4 and 0510 (G6, PB2) (Table 1). Because NCDV and 0510 have different $P$ serotypes (15), these cross-neutralization results should be mediated by the G serotype (G6).

Table 2 shows the result of neutralization assays with three monoclonal antibodies, B223-N7, B223-N1, and B641$\mathrm{N} 2 \mathrm{~b}$, which are directed to VP7 of B223 (G10), VP4 of B223 (PB3), and VP7 of B641 (G6), respectively. While B223-N1 neutralized both KK-3 and KN-4 in similar titers, B223-N7 neutralized KK-3 but not $\mathrm{KN}-4$. These results indicate that the P serotype of KN-4 is that of KK-3 (PB3) but that the G serotype of $\mathrm{KN}-4$ is different from that of $\mathrm{KK}-3$ (G10). A further complication, however, stemmed from the result that B641-N2b, which is G6 specific, did not neutralize $\mathrm{KN}-4$ (Table 2).

To determine the G serotype of strain $\mathrm{KN}-4$, the VP7 gene of KN-4 was sequenced (Fig. 1), and the deduced amino acid sequence was compared with the corresponding sequences of reference bovine rotavirus strains with $\mathrm{G} 6$ and $\mathrm{G} 10$ specificity (Fig. 2). The results shown in Table 3 indicated that the deduced amino acid sequence of $\mathrm{KN}-4$ was more similar to those of G6 strains (90.2 to $91.1 \%$ ) than to those of KK-3 and other G10 strains (84.4 to $85.6 \%$ ). Furthermore, when attention was focused on the amino acid at position 213 , which was previously shown to be selected with monoclonal antibodies in neutralization escape mutants, aspartic acid was present in the VP7 of KN-4 as well as in those of all G6 strains. This aspartic acid was replaced by arginine in the VP7s of KK-3 and 61A and by glycine in the VP7 of B223. We therefore concluded that the G serotype of $\mathrm{KN}-4$ is G6 (Fig. 2).

\section{DISCUSSION}

Standard neutralization assays with hyperimmune antisera are poor discriminators of $\mathbf{P}$ serotypes because the predominant antibody reactivity in hyperimmune serum is against glycoprotein VP7 (6). Reactivity with VP4 is detected when two viruses with distinct $G$ serotypes generate a one-way cross-neutralization with hyperimmune antiserum. Such sharing of $P$ serotype with two virus strains with different $G$ serotypes has never been reported to result in two-way cross-neutralization until now. Thus, the criterion for the definition of the rotavirus serotype originally proposed by Wyatt et al. (30) has been widely accepted for establishing a new G serotype (13).

During serological studies of bovine rotavirus strains isolated in Japan, we came across a complex situation in which one isolate $(\mathrm{KN}-4)$ showed two-way cross-neutralization not only with KK-3 (G10) but also with NCDV (G6). KK-3 and NCDV, which do not share either the G or the P serotype, showed no cross-reactivity in neutralization as- 
1 GGCTTTAAAAGCGAGAATTTCCGTTTGGCTAGCGGTTAGCTCCTTTTAATGTATGGTATTGAATATACCACAATTCTAATCTTCTTGGTA

91 TCAATCATACTGATAAATTATATTTTGAAATCAATAACAAGAATAATGGACTACATAATTTATAGATTTCTATTTGTCGTAGTTCTCATG

181 GCCATTGTCACGAGCGCGCAGAATTATGGAGTGAATTTACCCATTACAGGGTCAATGGATACTGCGTATGCAAACTCTACGCAAAATGAA

271 CCGTTTTTGACATCGACTCTTTGTTTATACTACCCGATCGAAGCATCAAACGAAATAGCAGACACAGAGTGGAGAAACACATTATCTCAA 361 CTATTTCTAACAAAAGGATGGCCGACAGGATCAGTGTATTTTAAAGAATACGCAGATATAGCAGCATTTTCAGTTGAACCACAACTGTAC 451 TGTGATTATAATATAGTTTTAATGAAATATGATTCAACACTAGAATTGGATATGTCAGAATTAGCTGATCTTATTTTGAACGAATGGTTA 541 TGCAATCCAATGGACATAACATTATATTACTACCAGCAAACCGACGAAGCAAATAAATGGATATCAATGGGTTCATCTTGTACAATTAAA 631 GTATGTCCGTTAAATACACAGACGCTTGGAATCGGGTGCTCAACAACTAACCCGGACACTTTTGAAACAGTTGCGACAGCAGAGAAACTA 721 GTAATTACTGACGTCGTAGACGGTGTAAATCATAAATTAGATGTAACGACTGCGACGTGTACAATACGCAACTGTAAAAAACTGGGTCCA 811 AGAGAAAACGTTGCAGTGATTCAAGTAGGTGGCGCGAACATATTAGACATAACAGCTGATCCAACGACTGCACCACAGACAGAAAGAATG 901 ATGCGAGTAAACTGGAAAAAATGGTGGCAGGTTTTTTATACAGTAGTTGACTATGTGAATCAAATAATTCAAGCAATGTCCAGAAGGTCT 991 AGATCACTAAATTCAGCTGCATTTTACTATAGGGTGTAGGTACATGTTAGATTAGAGTTGTATGATGTGACC

FIG. 1. Nucleotide sequence of the VP7 gene of bovine rotavirus strain $\mathrm{KN}-4$. Underlined bases indicate positions of initiation and termination codons.

says (15). To determine the $\mathrm{G}$ and $\mathrm{P}$ serotypes of $\mathrm{KN}-4$, we used neutralizing monoclonal antibodies previously shown to be specific for G6, G10, and PB3. The results obtained with these monoclonal antibodies confirmed that KK-3 and B223 shared not only the G serotype (G10) but also the P serotype (PB3) and that $K K-3$ and $K N-4$ had the same $P$ serotype (PB3). However, the monoclonal antibody specific for G6 (B641-N2b) did not neutralize $\mathrm{KN}-4$. Thus, there was no direct indication that the $\mathrm{G}$ serotype of $\mathrm{KN}-4$ was G6, although the results obtained by neutralization assays with hyperimmune antiserum strongly suggested that this was the case.

Since serological assays failed to unequivocally determine the $\mathrm{G}$ serotype of $\mathrm{KN}-4$, we sequenced the VP7 gene of $\mathrm{KN}-4$ and predicted its amino acid sequence. Comparison of the VP7 protein of $\mathrm{KN}-4$ with the VP7 proteins of reference bovine rotavirus strains possessing G6 (NCDV, UK, and B641) or G10 (B223 and 61A) specificity showed that the amino acid identity of $\mathrm{KN}-4$ and other G6 strains (90.2 to 91.1\%) was significantly higher than that of $\mathrm{KN}-4$ and G10

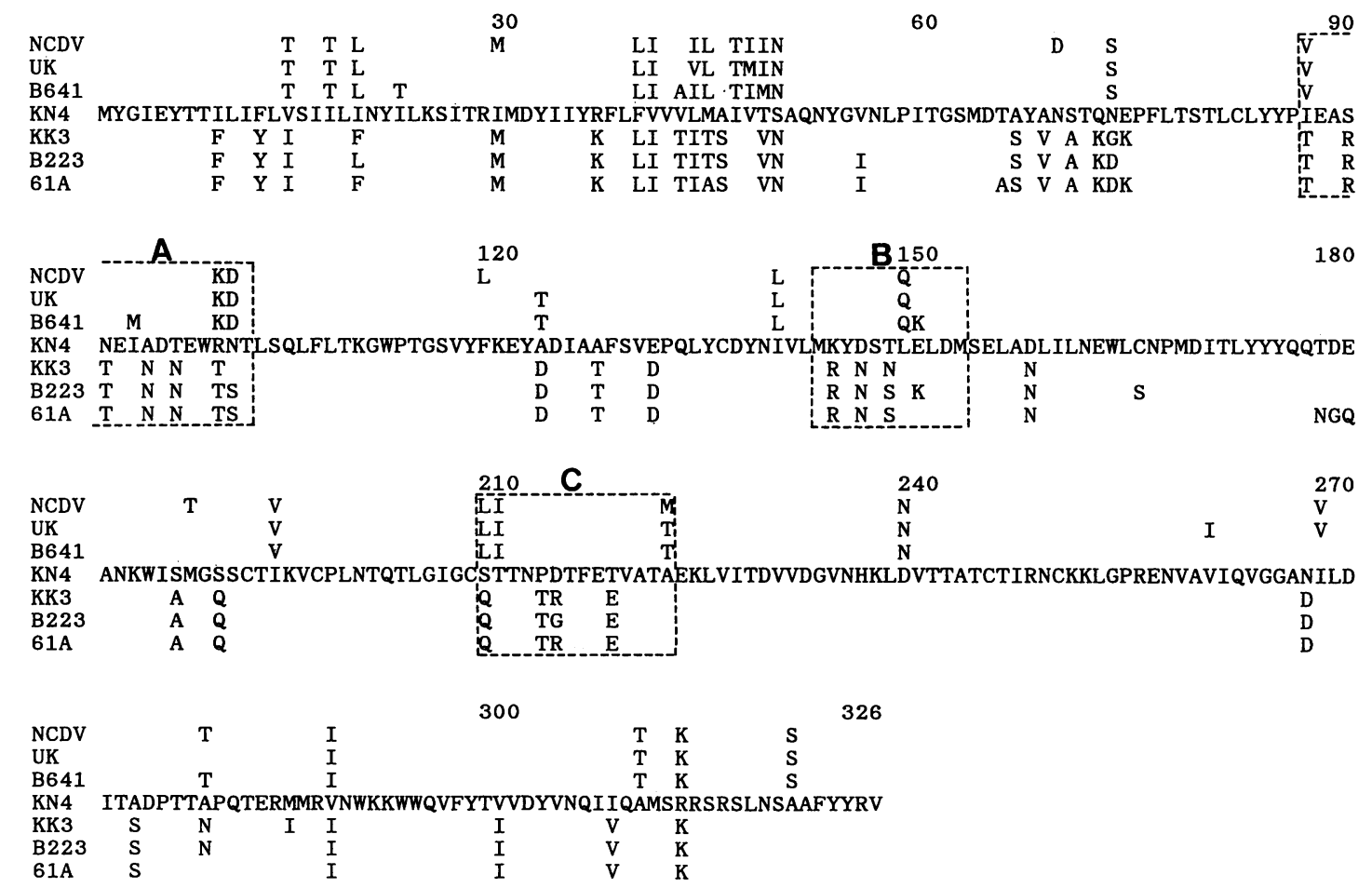

FIG. 2. Predicted amino acid sequence of the VP7 protein of bovine rotavirus strain KN-4. Differences in the corresponding amino acid sequences of serotype G6 strains are shown above that of $\mathrm{KN}-4$, and differences in the amino acid sequences of serotype G10 strains are shown below that of KN-4. The amino acid sequence of NCDV is from reference 7, that of UK is from reference 5, that of B641 is from reference 8, that of $\mathrm{KK}-3$ is from reference 28 , that of $\mathrm{B} 223$ is from reference 32 , and that of $61 \mathrm{~A}$ is from reference 27 . Three antigenic regions $(\mathrm{A}, \mathrm{B}$, and $\mathrm{C})$ predicted to be involved in virus neutralization are boxed. 
TABLE 3. Amino acid homologies of VP7 proteins of $\mathrm{KN}-4$ and various serotype $\mathrm{G} 6$ or $\mathrm{G} 10$ bovine rotavirus strains

\begin{tabular}{lccc}
\hline \multirow{2}{*}{$\begin{array}{c}\text { Virus } \\
\text { (G serotype) }\end{array}$} & \multicolumn{3}{c}{ \% VP7 homology with VP7 of strain ${ }^{a}:$} \\
\cline { 2 - 4 } & KN-4 & NCDV & KK-3 \\
\hline KN-4 & & 90.2 & 85.6 \\
NCDV (G6) & 90.2 & & 82.8 \\
UK (G6) & 91.1 & 96.9 & 82.8 \\
B641 (G6) & 90.2 & 96.3 & 82.8 \\
KK-3 (G10) & 85.6 & 82.2 & \\
B223 (G10) & 84.4 & 81.6 & 96.9 \\
61A (G10) & 85.0 & 82.8 & 96.6 \\
\hline
\end{tabular}

a The references for the VP7 protein sequences of the bovine rotavirus strains are listed in the legend to Fig. 2.

strains (84.4 to $85.6 \%$ ), indicating that $\mathrm{KN}-4$ is a $\mathrm{G} 6$ strain. The amino acid similarity between $\mathrm{KN}-4$ and other G6 strains, however, was lower than the similarity among reference G6 strains ( 96.3 to $96.9 \%$ ).

Three regions (A, B, and C), located at amino acids 87 to 101,142 to 152 , and 208 to 221 , respectively, have been shown to be involved in virus neutralization $(4,14,26)$. At four sites (amino acids 87, 99, 100, and 208) within region $A$ or $\mathrm{C}$, amino acid substitutions which are not shared with either G6 or G10 strains were observed. Furthermore, at two sites (amino acids 148 and 209), one each in regions B and C, amino acid residues were shared by $\mathrm{KN}-4$ and $\mathrm{G} 10$ strains (but not by G6 strains). Thus, the VP7 sequence of $\mathrm{KN}-4$ was likely to be somewhat different from the consensus sequence of G6 strains. It should also be noted, however, that such a slight antigenic difference, if present, was not detected by neutralization assays with hyperimmune antisera.

This study strongly suggests the need to adopt a binary system to describe serotypes of bovine rotavirus strains. For this purpose, some molecular assays need to be developed to supplement or replace the assays based on monoclonal antibodies which are still under development.

\section{ACKNOWLEDGMENTS}

We thank Y. Murakami, T. Murakami, Y. Hoshino, and R. I. Glass for providing us with various rotavirus strains used in this study.

This work was supported in part by a grant-in-aid for scientific research from the Ministry of Education, Science, and Culture of Japan.

\section{REFERENCES}

1. Browning, G. F., R. M. Chalmers, T. A. Fitzgerald, and D. R. Snodgrass. 1991. Serological and genomic characterization of L338, a novel equine group A rotavirus G serotype. J. Gen. Virol. 72:1059-1064.

2. Browning, G. F., T. A. Fitzgerald, R. M. Chalmers, and D. R. Snodgrass. 1991. A novel group A rotavirus G serotype: serological and genomic characterization of equine isolate FI23. J. Clin. Microbiol. 29:2043-2046.

3. Clark, H. F., Y. Hoshino, L. M. Bell, J. Grofi, G. Hess, P. Bachman, and P. A. Offit. 1987. Rotavirus isolate WI61 representing a presumptive new human serotype. J. Clin. Microbiol. 25:1757-1762.

4. Dyall-Smith, M. L., I. Lazdins, G. W. Tregear, and I. H. Holmes. 1986. Location of the major antigenic sites involved in rotavirus serotype-specific neutralization. Proc. Natl. Acad. Sci. USA 83:3465-3468.

5. Elleman, T. C., P. A. Hoyne, M. L. Dyall-Smith, I. H. Holmes, and A. A. Azad. 1983. Nucleotide sequence of the gene encoding the serotype specific glycoprotein of UK bovine rotavirus.
Nucleic Acids Res. 11:4689-4701.

6. Estes, M. K., and J. Cohen. 1989. Rotavirus gene structure and function. Microbiol. Rev. 53:410-449.

7. Glass, R. I., J. Keith, O. Nakagomi, T. Nakagomi, J. Askaa, A. Z. Kapikian, R. M. Chanock, and J. Flores. 1985. Nucleotide sequence of the structural glycoprotein VP7 gene of Nebraska calf diarrhea virus rotavirus: comparison with homologous genes from four strains of human and animal rotaviruses. Virology 141:292-298.

8. Hardy, M. E., G. N. Woode, Z. Xu, and M. Gorziglia. 1991. Comparative amino acid sequence analysis of VP4 for VP7 serotype 6 bovine rotavirus strains NCDV, B641, and UK. J. Virol. 65:5535-5538.

9. Hoshino, Y., M. M. Sereno, K. Midthun, J. Flores, R. M. Chanock, and A. Z. Kapikian. 1987. Analysis by plaque reduction neutralization assay of intertypic rotaviruses suggests that gene reassortment occurs in vivo. J. Clin. Microbiol. 25:290 294.

10. Hoshino, Y., M. M. Sereno, K. Midthun, J. Flores, A. Z. Kapikian, and R. M. Chanock. 1985. Independent segregation of two antigenic specificities (VP3 and VP7) involved in neutralization of rotavirus infectivity. Proc. Natl. Acad. Sci. USA 82:8701-8704.

11. Hoshino, Y., R. G. Wyatt, H. B. Greenberg, J. Flores, and A. Z. Kapikian. 1984. Serotypic similarity and diversity of rotaviruses of mammalian and avian origin as studied by plaque-reduction neutralization. J. Infect. Dis. 149:694-702.

12. Isegawa, Y., J. Sheng, Y. Sokawa, K. Yamanishi, O. Nakagomi, and S. Ueda. Selective amplification of cDNA sequence from total RNA by cassette-ligation mediated polymerase chain reaction (PCR): application to sequencing $6.5 \mathrm{~kb}$ genome segment of hantavirus strain B1. Mol. Cell. Probes, in press.

13. Kapikian, A. Z., and R. M. Chanock. 1990 . Rotaviruses, p. 1353-1403. In B. N. Fields, R. M. Chanock, M. S. Hirsch, J. L. Melnick, T. P. Monath, and B. Roizman (ed.), Virology. Raven Press, New York.

14. Mackow, E. R., R. D. Shaw, S. M. Matsui, P. T. Vo., D. A. Benfield, and H. B. Greenberg. 1988. Characterization of homotypic and heterotypic VP7 neutralization sites of rhesus rotavirus. Virology 165:511-517.

15. Matsuda, Y., O. Nakagomi, and P. A. Offit. 1990. Presence of three P types (VP4 serotypes) and two G types (VP7 serotypes) among bovine rotavirus strains. Arch. Virol. 115:199-207.

16. Matsuno, S., A. Hasegawa, A. Mukoyama, and S. Inouye. 1985. A candidate for a new serotype of human rotavirus. J. Virol. 54:623-624.

17. Mebus, C. A., M. Kono, N. R. Underdahl, and M. J. Twienhaus. 1971. Cell culture propagation of neonatal calf diarrhea (scours) virus. Can. Vet. J. 12:69-72.

18. Murakami, T., N. Hirano, K. Chitose, K. Tsuchiya, K. Ono, F. Sato, Y. Suzuki, and Y. Murakami. 1987. A survey on bovine rotavirus type-1-associated neonatal calf diarrhea in a beef herd. Jpn. J. Vet. Sci. 49:23-30.

19. Murakami, Y., N. Nishioka, Y. Hashiguchi, and C. Kuniyasu. 1983. Serotypes of bovine rotaviruses distinguished by serum neutralization. Infect. Immun. 40:851-855.

20. Nakagomi, O., T. Nakagomi, K. Akatani, and N. Ikegami. 1989. Identification of rotavirus genogroups by RNA-RNA hybridization. Mol. Cell. Probes 3:251-261.

21. Offit, P. A., and G. Blavat. 1986. Identification of the two rotavirus genes determining neutralization specificities. J. Virol. 57:376-378.

22. Qian, Y., and K. Y. Green. 1991. Human rotavirus strain 69M has a unique VP4 as determined by amino acid sequence analysis. Virology 182:407-412.

23. Ruiz, A. M., I. V. López, S. López, R. T. Espejo, and C. F. Arias. 1988. Molecular and antigenic characterization of porcine rotavirus YM, a possible new rotavirus serotype. J. Virol. 62:4331-4336.

24. Sanger, F., S. Nicklen, and A. R. Coulson. 1977. DNA sequencing with chain-terminating inhibitors. Proc. Natl. Acad. Sci. USA 74:5463-5467.

25. Snodgrass, D. R., T. Fitzgerald, I. Campbell, F. M. M. Scott, 
G. F. Browning, D. L. Miller, A. J. Herring, and H. B. Greenberg. 1990. Rotavirus serotypes 6 and 10 predominate in cattle. J. Clin. Microbiol. 28:504-507.

26. Taniguchi, K., Y. Hoshino, K. Nishikawa, K. Y. Green, W. L. Maloy, Y. Morita, S. Urasawa, A. Z. Kapikian, R. M. Chanock, and M. Gorziglia. 1988. Cross-reactive and serotype-specific neutralization epitopes on VP7 of human rotavirus: nucleotide sequence analysis of antigenic mutants selected with monoclonal antibodies. J. Virol. 62:1870-1874.

27. Taniguchi, K., Y. Pongsuwanna, M. Choonthanom, and S. Urasawa. 1990. Nucleotide sequence of the VP7 gene of a bovine rotavirus (strain 61A) with different serotype specificity from serotype 6. Nucleic Acids Res. 18:4613.

28. Taniguchi, K., T. Urasawa, Y. Pongsuwanna, M. Choonthanom, C. Jayavasu, and S. Urasawa. 1991. Molecular and antigenic analyses of serotype 8 and 10 of bovine rotaviruses in Thailand.
J. Gen. Virol. 72:2929-2937.

29. Urasawa, S., T. Urasawa, F. Wakasugi, N. Kobayashi, K. Taniguchi, I. C. Lintag, M. C. Saniel, and H. Goto. 1990. Presumptive seventh serotype of human rotavirus. Arch. Virol. 113:279-282.

30. Wyatt, R. G., H. B. Greenberg, W. D. James, A. L. Pittman, A. R. Kalica, J. Flores, R. M. Chanock, and A. Z. Kapikian. 1984. Definition of human rotavirus serotypes by plaque reduction assay. Infect. Immun. 37:110-115.

31. Xu, L., D. Harbour, and M. A. McCrae. 1991. Sequence of the gene encoding the major neutralization antigen (VP7) of serotype 10 rotavirus. J. Gen. Virol. 72:177-180.

32. Zheng, S., G. N. Woode, D. R. Melendy, and R. F. Ramig. 1989. Comparative studies of the antigenic polypeptide species VP4, VP6, and VP7 of three strains of bovine rotavirus. J. Clin. Microbiol. 27:1939-1945. 